\title{
MODELING AND SIMULATION METHOD TO FIND AND ELIMINATE BOTTLENECKS IN PRODUCTION LOGISTICS SYSTEMS
}

\author{
Pawel Pawlewski \\ Marek Fertsch \\ Institute of Management Technology \\ Poznan University of Technology \\ Ul.Strzelecka 11 \\ Poznan, 60-965, POLAND
}

\begin{abstract}
The paper presents the method of modeling and simulation of production logistics systems. Finding and eliminating bottlenecks is the main goal of this method. Production system is identified using IDEF0 methodology. The model is constructed as a system of equations, which describe the elements of the production system in the relationships between them. The special category of resources - logistics resources is distinguished. A special parameter called "flow" is introduced. The algorithms to compute this parameter and to use it in order to find and eliminate bottlenecks are described. The results of simulation experiment are presented.
\end{abstract}

\section{INTRODUCTION}

The method of the fast analysis of production logistics systems using simulation was developed by the authors of this paper. The suggested simulation represents MRP simulation type (Ingalls 2008; Lee, Son and Wysk 2007). However, due to some of its features, the simulation exceeds the typical range of MRP kind of simulation. It is assumed that MRP simulations are the forecasting 'what-if' simulations which are usually related to specific, individual situations - case study (Byme and Bakir 1999). The proposed method can be located between operational and tactic level. (Kosturiak and Gregor 1999). See Figure 1. The presented solution suggests the method of modelling the production logistics system and the method of finding and eliminating bottlenecks with use of simulation. This is a solution of a universal kind, which makes it possible to apply the method to analyzing various structures of production processes.

The method provides a manager with an opportunity to compare the resources available in the production logistics system in a certain time frame with the resources requirement resulting from the production programme within the same period. Additionally the method gives recommendations referring to the re-allocation of particular resources, enabling a simulation of various variants of resources allocation and a comparison of selected variants.

The method is based on a model of a production system (Pacholski, Cempel and Pawlewski 2009). The model is constructed as a system of equations, which describe the elements of the production system and the relationships between them. Special consideration is given to the precise description of resources identification, availability and requirements. A special category of resources, resources of the logistic system (logistics resources) is separated. The creation of this resources category is based on one special feature - the possibility of sharing it between particular operations connected to the material flow. For example, internal transport equipment can be used for the simultaneous translocation of different types of material, and the storage area belonging to one production unit can serve another production unit, too. 


\section{Pawlewski and Fertsch}

Resulting from a special feature of logistics resources, the chance of an apparent re-allocation and sharing of the resources at the same time, operations of these kinds of resources are described within the model. A special parameter called "flow" has also been introduced. This parameter is used for describing the possibly undisturbed flow of material between the structural units (resource-operation unit - RO) of manufacturing. The "flow" is defined as the difference between the sum of all the resource requirements for production units connected by the material flow and the sum of all the resources available for these units. This parameter is defined for each kind of logistics resource.

Paper is organized as follow: in section 2 the production system is identified and its graph is presented, theory of modeling and simulation method is described using formal definitions in section 3 , section 4 contains results of simulation experiment and suggestions to eliminate bottlenecks, final conclusions are stated in section 5 .

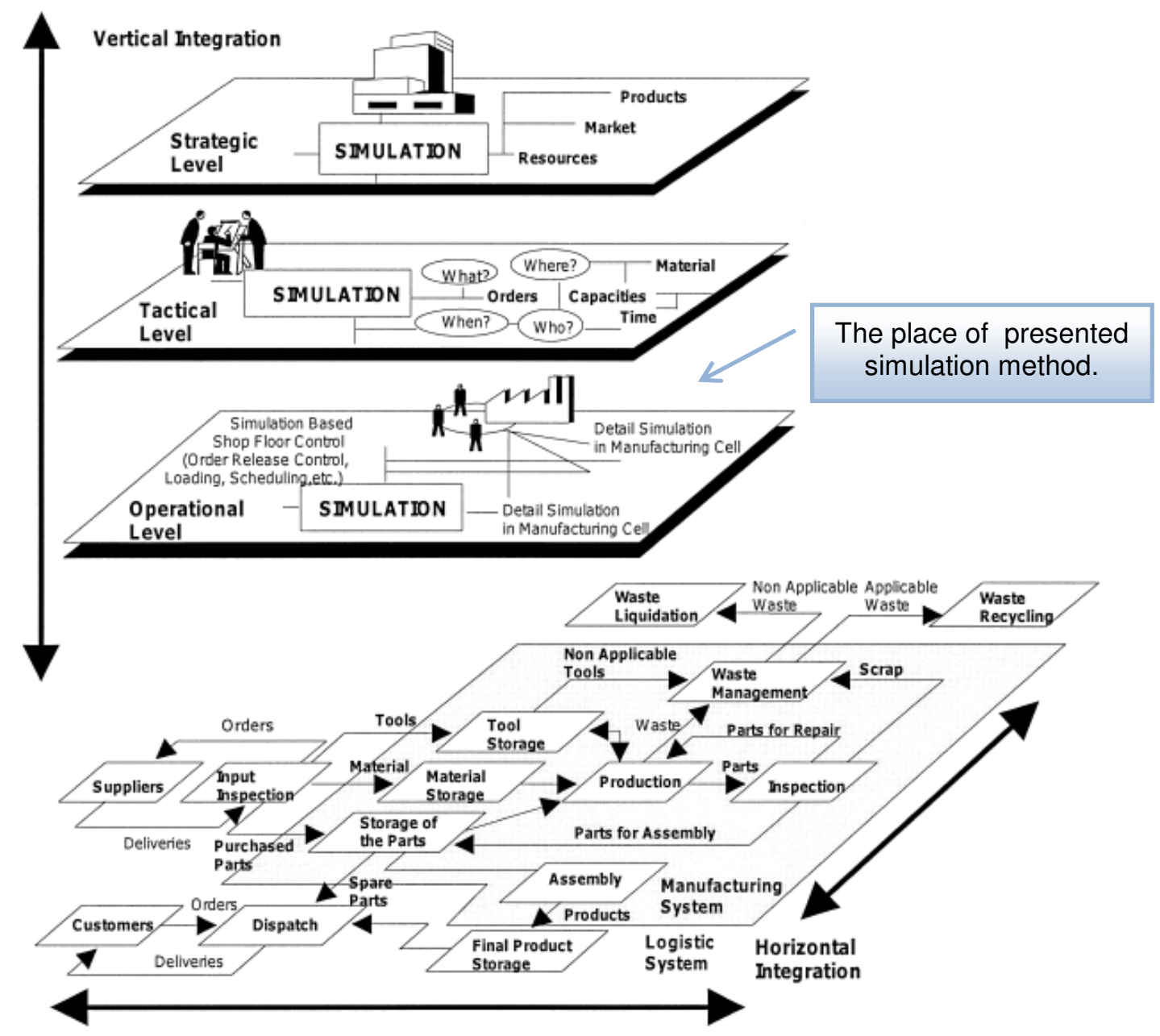

Figure 1: Integration of simulation modelling in enterprise (Kosturiak and Gregor 1999) 


\section{Pawlewski and Fertsch}

\section{PROCDUCTION SYSTEM IDENTIFICATION}

The research was done based on the data collected for the sake of projects developed by the Institute of Management Technology at Poznan University of Technology and ordered by one of machine-building industry enterprises. The purpose of the order was to introduce a system called KWSP based on the MRP II concept. The investigated object is a typical cooperation company, since all the finished products are units, components and parts which are passed on for further assembly. The company specializes in the production of units and components for agricultural machinery, especially:

- three-nodes suspension systems for tractors

- straw shredders as parts of harvesters

- $\quad$ other parts and units (e.g. frames for cultivators).

The machinery installed in the enterprise is typical for machine-building companies and it mainly consists of: turning lathes, milling machines, rolling mills, drilling machines, presses, frame saws and guillotine shears, fettling and cleaning machines, semi-automatic welder and automatic machine for oxygen-cutting and assembly, locksmith's and painting stands. A full list of machines grouped into RO (groups of uniform stands according to MRP II concept) is shown in Table 1.

Table 1: List of machines grouped into RO

\begin{tabular}{|l|l|}
\hline RO number & \multicolumn{1}{|c|}{ RO Name and Type } \\
\hline 1 & Semi-automatic welders (CO2) 10 pieces \\
\hline 2 & Fettling machine OWD 1000, OPK 1000 \\
\hline 3 & Paint shop \\
\hline 4 & Guillotine shears ScTP 16 \\
\hline 5 & Hydraulic press \\
\hline 6 & Tumbling barrel OB1000 2 szt \\
\hline 7 & Abrasive cut-off machine BSA 5 \\
\hline 8 & Drilling machine SKT, BKR \\
\hline 9 & Loftsman's stand \\
\hline 10 & Turning lathes SU-50A, TPC-40x1500, TPC40x1000 \\
\hline 11 & Centreless grinder S88 75 2 pieces \\
\hline 12 & Rolling mill UPW 12,5x70 3pieces \\
\hline 13 & Multiple-spindle drilling machine BKG63 \\
\hline 14 & Drilling machine WKA40 \\
\hline 15 & Horizontal milling machine NRD \\
\hline 16 & Milling machine FSS 400V \\
\hline 17 & Oxygen-cutting stand \\
\hline 18 & Automatic machine for oxygen-cutting \\
\hline 19 & Locksmith's stand \\
\hline 20 & Automatic lathe APA25 4 pieces \\
\hline 21 & Hardening furnace PEK 3 \\
\hline 22 & Universal shears NU 25 \\
\hline 23 & Friction screw press OPC 120 \\
\hline 24 & Assembly stand \\
\hline
\end{tabular}

The diagram of the production structure of the company is shown in Figure 2. The production structure consists of four technology-oriented production units, which are managed by foremen. There are no object-oriented production units in the structure of the company. 


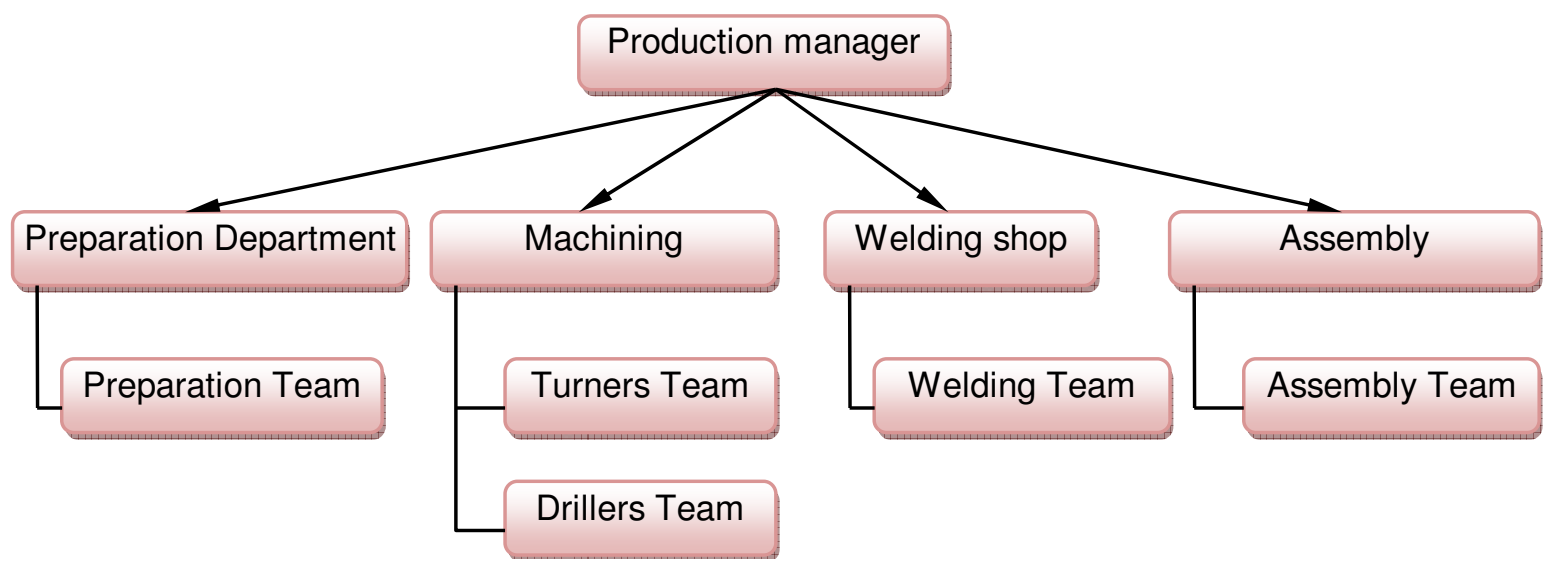

Figure 2: Production structure

The full production assortment includes 328 items. The phase of the final assembly of ten assortment items was subjected to an analysis and simulation. At this stage, the production system consists of a set of 25 structural units RO. Based on a full set of data imported from KWSP system, a set of data including the final assembly phase was prepared. The model of the production logistic system was developed on the basis of technological routes obtained from data included in MRP II system. It refers to the final assembly of ten assortment items. The model is show in the form of a graph in Figure 3.

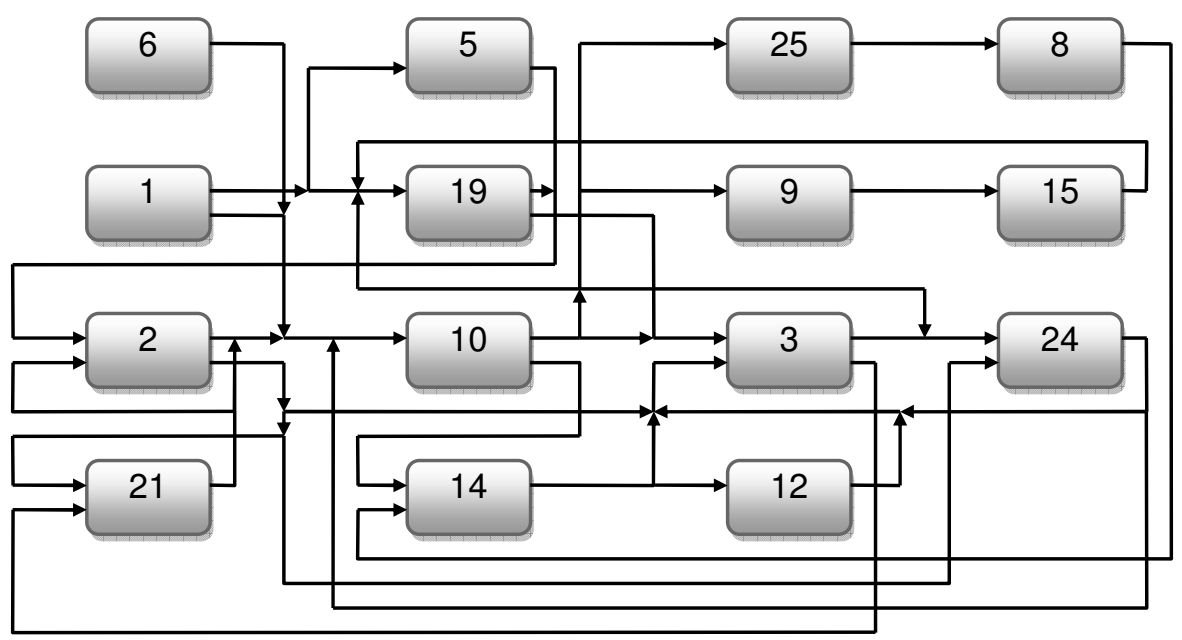

Figure 3: Graph of the analyzed production system

\section{MODELING AND SIMULATION METHOD - THEORY}

This section presents formal definitions which are necessary to define "model of flow" of materials within the production logistics system. Based on defined structural unit $\mathrm{RO}$ - resource operation, the list of pairs $\mathrm{RO}$ is built, the logistics flow matrix is formed and finally algorithm to find bottlenecks is presented.

Definition 1 Assortment - set of products of different complexity, manufactured in the analyzed production system

$$
A=\left\{a_{1}, \ldots \ldots, a_{s}\right\}
$$

where: $a_{l}$ - element of assortment set, $\quad l$-product, $\quad l \in\langle 1, s\rangle, s$-number of products in the analyzed set. 
Every l element of $a_{l}$ is described by the following parameters: $a_{l}=(D, F, R)$

Definition 2 Parameter $D_{l}$ - complexity of litem, is a pair

$$
D_{l}=\left(a_{k}, d_{l k}\right)
$$

where: $a_{k}$-element $k$ of products set, $k \neq 1, a_{l}$-element of $a_{k}$ which is characterized by directly lowest level of complexity $d_{l k}-$ recurrently (number of pieces) of product $l$ in product $k$

Definition 3 Parameter $\boldsymbol{F}_{l}$ technological process, which is the set of technological operation characteristics. The characteristics are given in predefined order, according to operations flow.

$$
F_{l}=\left\{f_{1}, \ldots . . ., f_{m l}\right\}
$$

where: $\quad f_{i}$ - consists of three elements

$$
f_{i}=\left(t_{p z}, t_{j}, \tau\right)
$$

and: $t_{p z}$ - setup time, $t_{j}$ - lead time, $\boldsymbol{\tau}$ - normative interoperation break, $m l$-number of elements.

Definition 4 Parameter $\boldsymbol{R}$ - resources requirements defined for each element $l$ of set $A$.

$$
R=R_{1}+R_{2}
$$

and: $R_{I}$ - is requirements of operations

$$
\begin{aligned}
R_{1} & =\left[r_{1}, \ldots,\left(\ldots, r_{i}, \ldots\right)_{m}\right] \\
\text { where: } \boldsymbol{r}_{i} \text { - is a set } & r_{1}=\left\{z_{i}, \omega\right\}
\end{aligned}
$$

and: $z_{i}$-resource $i, i \in\langle 1, n\rangle, n$-number of resource $i, \omega_{i}$-use of resource $i, m$-number of operations,

\section{$R_{2}-$ is requirements not connected with any operations}

$$
R_{2}=\left[\ldots,\left\{z_{i}, \omega_{i}\right\}, \ldots\right]
$$

Definition 5 Set of resources - all materials necessary to manufacture products in the predefined system.

$$
Z=\{z l, z n\}
$$

where : $z_{i}$ - element of resources set, $i$ - resource, $i \in\langle 1, n\rangle, n$-number of resources.

Each of , $i$ " elements of $z_{i}$ is characterized by parameters:

$$
z_{i}=\left(q_{i}, c_{i}\right)
$$

where: $q_{i}-$ size of resource , $i ”$ accessible in analyzed time,

$c_{i}-$ cost of resource , $i$ " dependent on its accessibility in time analyzed

$$
c_{i}=q_{i} *\left(c_{i N} i+c_{i M i}\right)
$$

where: $c_{i N j}$ - price of resource , $i$ ” in analyzed time,

$c_{i M j}-$ cost of storing and maintaining resource , $i$ " in time analyzed.

Definition 6 Production program is one of the features which is crucial for resources. Production program is a function of two parameters:

$$
P_{l}=f\left(a_{l}, \Delta t\right)
$$

Where: $\boldsymbol{a}_{l}$ - item , $i$ " of assortment set, $\Delta t$ - analyzed time period

Definition 7 RO (Resource Operation) is a structural unit which contains elements of a technological process and resources required to perform this process.

$$
R O_{i}=\left(F^{\prime}, R^{\prime}\right)
$$

Where: $F$ ' is a technological process, which consists of the set of the threes describing each technological operation and can be described as:

$$
F^{\prime}=\left(f_{i}, \ldots, f_{m l}\right)
$$

$R^{\prime}$ is a parameter describing resource requirements for each product offer as an assortment and is described as: $R^{\prime}=\left(r_{m}, \ldots, r_{n}\right)$. If triplets of $f_{i}$ belong to the particular $R O_{j}$ then it cannot belong to any other $R O_{k}$ for each $j$ which is different from $k$ 


$$
\begin{array}{r}
\text { Pawlewski and Fertsch } \\
\bigcap_{f i} \in R O_{j}: f_{i} \notin R O_{k} \& k \neq j
\end{array}
$$

Definition of RO was developed as a result of the analysis of IDEF0 methodology and systems based on MRPII concept. RO is connected with ICOM concept applied in IDEF0 methodology. The benefit of IDEF0 methodology is that it allows combining system functions like activities, actions, processes, and operations, functional relationships and data that support integration of systems. The main components of IDEF0 model are the diagrams which are constructed of boxes and arrows. The box is respondent to the function (activity), the arrows identify data or objects needed or produced by the function (ICOM : I - Input, $\mathrm{C}$ - Control, $\mathrm{O}$ - Output, $\mathrm{M}$ - Mechanism). In the proposed by the authors approach RO refers to the description of Mechanism and Function.

To define the concept logistics resources we use its presentation in form of logistic matrix including following dimension: logistics processes and logistics subsystems. Logistic matrix presents Table 2. In following matrix:

- columns present typical logistic subsystems

- logistic processes like delivery, inventory management, packing, loading, transport etc. are put in rows.

The list of logistic processes was created according to work (Korzeniowski, Skrzypek and Szyszka 1996), other specification of a number of logistic processes can be found in (ELA 1991), these processes can be performed potentially in every subsystem. Logistic resources are connected with every element of a logistic matrix, so they are connected with both specific logistic process and a subsystem which this process performs. Defining boundaries of a logistic system resources can be treated as separate subsystems e.g. area, transport, inventory, staff. It is assumed that in a short operational time logistic resources are available. Logistic resources are coherent if they are treated as a subsystem of the logistic system.

Table 2: Logistic matrix (Korzeniowski, Skrzypek and Szyszka 1996).

\begin{tabular}{|c|c|c|c|c|c|}
\hline \multicolumn{7}{|c|}{ Economic logistics } \\
\hline & $\begin{array}{c}\text { Delivery Lo- } \\
\text { gistics }\end{array}$ & $\begin{array}{c}\text { Production } \\
\text { Logistics }\end{array}$ & $\begin{array}{c}\text { Distribution } \\
\text { Logistics }\end{array}$ & $\begin{array}{c}\text { Service Logis- } \\
\text { tics }\end{array}$ & $\begin{array}{c}\text { Waste Logis- } \\
\text { tics }\end{array}$ \\
\hline $\begin{array}{c}\text { Logistics proc- } \\
\text { esses }\end{array}$ & \multicolumn{7}{|c|}{$\rightarrow \quad$ Material Flow } \\
\hline Delivery & + & + & + & + & + \\
\hline Inventory Mng. & + & + & + & + & + \\
\hline Storing & + & + & + & + & + \\
\hline Packing & + & + & + & + & + \\
\hline Transport & + & + & + & + & + \\
\hline Communication & + & + & + & + & + \\
\hline Management & + & + & + & + & + \\
\hline & $+\quad$ & \multicolumn{7}{|l|}{ Information Flow } \\
\hline
\end{tabular}

Definition 8 Each element of resources requirements $R^{\prime}$ is connected with a parameter $\boldsymbol{r r}$ - requested resource to implement the program $P$ in the considered time interval $\Delta t$. It is a parameter determining the number of uses ( $\omega$-definition 4$)$ of a given resource required to implement the program $P$.

Definition 9 Each element of resources requirements $R$ ' is connected with parameter $\boldsymbol{d r}$ - disposed resource to implement the program $P$ in the considered time interval $\Delta$ t. It is a parameter determining availability of a given resource while the program $P$ is determined though the size of the resource expressed by appropriate units of measure. 
Definition 10 Total demand for a resource for a given RO is a sum of individual demands for this resource, requested to produce all the details according to the production program and time per unit.

$$
Z C_{i}=\sum_{l=1}^{s}\left(\omega_{l} * P_{l} * t_{l}\right)
$$

where: $\omega_{l}$ - use of resource, $P_{l}$ - production program, $t_{l}$ - time per unit

Definition 11 Flow with reserve occurs when $R O$ has a reserve for any element of resource requirements $R^{\prime}$, which means that the difference between the required resource and the disposed resource is less than zero.

$$
r r-d r<0
$$

Definicja 12 Balanced flow occurs when $R O$ is balanced for any element of resource requirements $R$ ', which means there is no difference between the required resource and the disposed resource.

$$
r r-d r=0
$$

Definition 13 Flow with deficit occurs when RO has a deficit for any element of resource requirements $R^{\prime}$, which means that the difference between the required resource and the disposed resource is more than zero.

$$
r r-d r>0
$$

Definition 14 Direct sequence relation symbol: $\rightarrow R O_{j}$ is in the direct sequence relation with $R O_{i}$, which is written as

$$
R O_{j} \rightarrow R O_{i}
$$

if in the production process $R O_{j}$ is a successive element in relation to $R O_{i}$.

Definition 15 Indirect sequence relation symbol : $\Rightarrow R O_{k}$ is in the indirect sequence relation with $R O_{i}$, which is written as :

$$
R O_{k} \Rightarrow R O_{i}
$$

if in the production process there is only one $R O_{j}$, which is in the relation: $R O_{k} \rightarrow R O_{j}$ and $R O_{j} \rightarrow R O_{i}$

Definition 16 Operation of adding (shifting) logistics resources symbol :+. For RO, which are in the direct or indirect sequence relation, an operation of adding (shifting) an arbitrary logistics resource $r_{m}$ can be performed only in the situation when the preceding $R O$ have a reserve within the resource.

$$
r_{m} \in R O_{j}=r_{m} \in R O_{i}+r_{m} \in R O_{j}: d r_{m}-r r_{m} \in R O_{i}>0
$$

where:

$s$ - size of $R O$ files, which are in relation: $R O_{j} \rightarrow R O_{i}$ or $R O_{j} \Rightarrow R O_{i}$, and have a reserve within the given resource $r m$, i.e. the condition is met: $\quad d r_{m}-r r_{m}>0$

Definition 17 Pairs list - set of pairs $\left\{R O_{l}, R O_{k}\right\}$, where $R O$ 's are in relation: $R O_{j} \rightarrow R O_{i}$ or $R O_{j} \Rightarrow R O_{i}$

Definition 18 Operation of balancing the flow symbol: $\oplus$ Operation of balancing the flow occurs for the pair $R O$ :

$$
R O_{l} \oplus R O_{k}: R O_{l} \rightarrow R O_{k} \vee R O_{l} \Rightarrow R O_{k}
$$

which are in direct or indirect sequence relation.

The algorithm of the operations of balancing the flow for the pair $\left\{R O_{l}, R O_{k}\right\}$ is shown in Figure 4.

Definition 19 The idea of the analysis of coincidence matrix $R O$ is to identify RO pairs for which the operation of balancing the flows can be performed. The algorithm of the coincidence matrix analysis is presented in the work (Pacholski, Cempel and Pawlewski 2009). The analysis resulted in a file of RO pairs for which the operation of balancing the flows can be performed. 


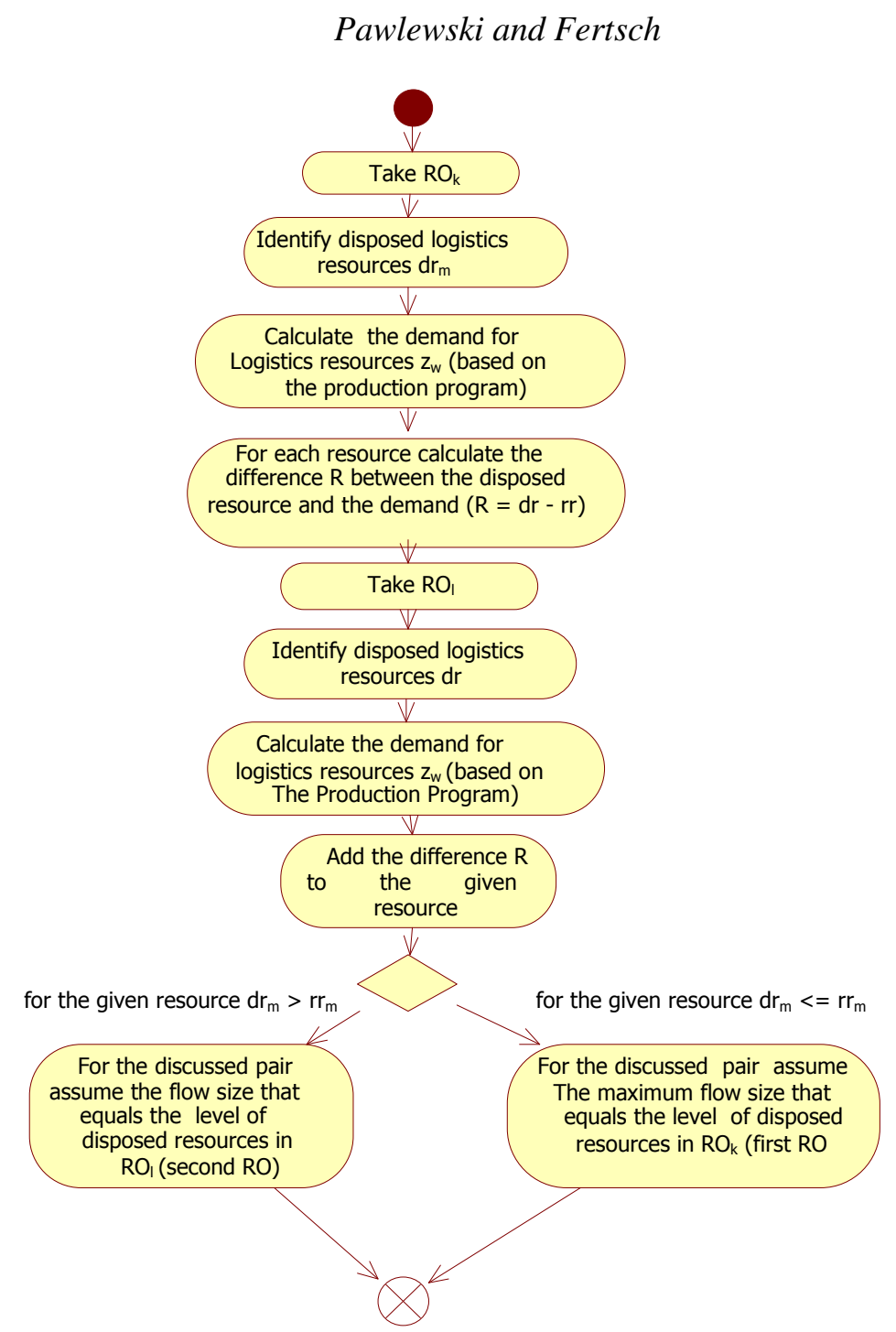

Figure 4:Algorithm of balancing the flow for the pair $\left(\mathrm{RO}_{\mathrm{l}}, \mathrm{RO}_{\mathrm{k}}\right)$

Definition 20 The logistic flow matrix is a three-dimensional matrix $n \times m \times s-$ Figure 5 where:

$n-i$ s the size of file $R O$

$m$ - is the size of set of logistic resources

$s$-is the greatest number of any RO appearances in pairs in the file of pairs $R O$ (definition 17)

Logistic flows matrix is built based on the contents of the file of pairs RO. The algorithm of forming the logistic flows matrix structure is shown in Figure 6. The following denotations were taken on:

$L$ - logistic flows matrix with the dimension $n \times m \times s$

$S$ - auxiliary matrix with the dimension $n \times m$, used to store the position numerators in the logistic flows matrix in the direction s. 


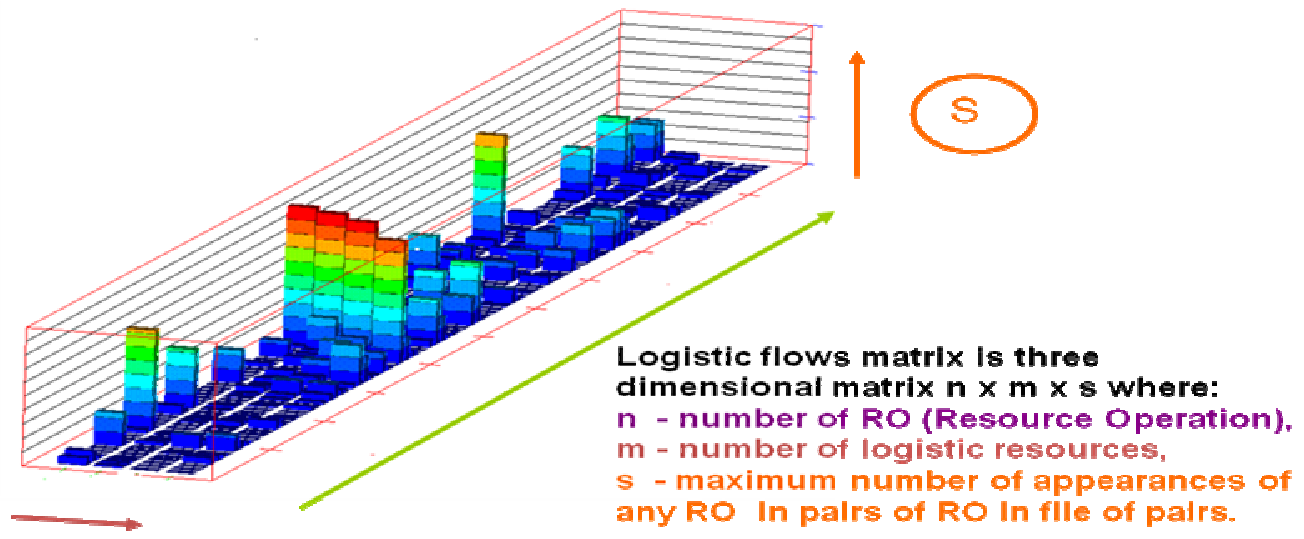

Figure 5: Logistics flow matrix

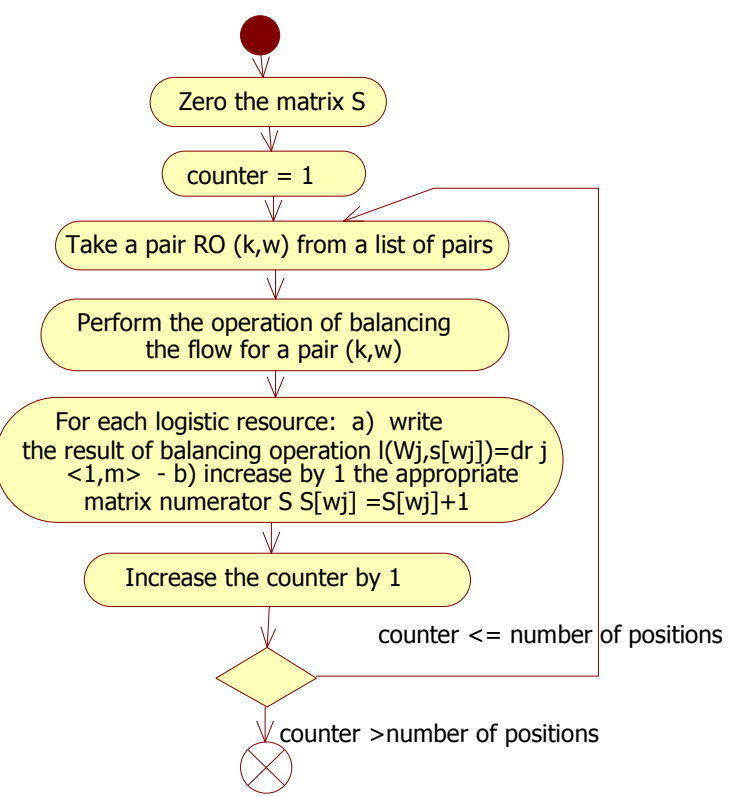

Figure 6: Algorithm of forming the structure of logistic flows matrix

Definition 21 The idea of the analysis of logistic flows is to review the flows matrix $L$ in the direction $s$ and to compare the results of the balancing operation for each $R O$ and logistic resource. The algorithm of the logistic flows analysis and inference is shown in Figure 7. 


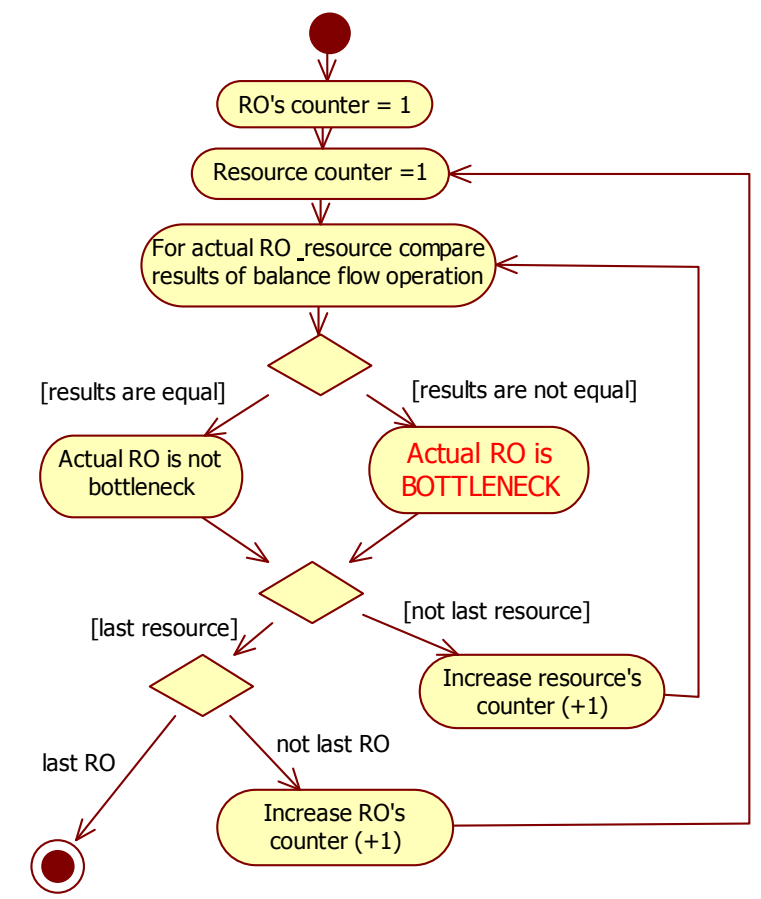

Figure 7: Algorithm of bottlenecks identification.

\section{NUMERICAL SIMULATION EXPERIMENT}

The data for this experiment were collected in a company. The output of the MRP system was used in addition to other sources. Performed experiment based on changes of the available resources. It allows the elimination of "bottle-necks" in the production logistics system. Table 3. presents a combination of some of the results of a balancing operation with structural unit RO10. This unit was connected to the following units: RO1, RO2, RO21, RO24, RO3, RO5, RO6 and RO19. See Figure 3.

Table 3: Results of the flow balancing for the structural unit RO10 with the step change of the amount of the available resources RO pairs in which $\mathrm{RO} 10$ in following relationship exists.

\begin{tabular}{|c|c|c|c|c|c|c|c|c|}
\hline $\begin{array}{l}\text { Level of available } \\
\text { resources }\end{array}$ & $1-10$ & $2-10$ & $21-10$ & $24-10$ & $3-10$ & $5-10$ & $6-10$ & $19-10$ \\
\hline 26.4 & 26.4 & 26.4 & 26.4 & 13.2 & 13.2 & 13.2 & 13.2 & 13.2 \\
\hline 27.4 & 27.4 & 27.4 & 27.4 & 13.2 & 13.2 & 27.4 & 27.4 & 13.2 \\
\hline 28.4 & 28.4 & 28.4 & 28.4 & 13.2 & 13.2 & 28.4 & 28.4 & 13.2 \\
\hline 29.4 & 29.4 & 29.4 & 29.4 & 13.2 & 13.2 & 29.4 & 29.4 & 13.2 \\
\hline 30.4 & 30.4 & 30.4 & 30.4 & 13.2 & 13.2 & 30.4 & 30.4 & 13.2 \\
\hline 31.4 & 31.4 & 31.4 & 31.4 & 13.2 & 31.4 & 31.4 & 31.4 & 13.2 \\
\hline 32.4 & 32.4 & 32.4 & 32.4 & 32.4 & 32.4 & 32.4 & 32.4 & 13.2 \\
\hline 33.4 & 33.4 & 33.4 & 33.4 & 33.4 & 33.4 & 33.4 & 33.4 & 13.2 \\
\hline 34.4 & 34.4 & 34.4 & 34.4 & 34.4 & 34.4 & 34.4 & 34.4 & 34.4 \\
\hline
\end{tabular}

Table 3 shows how disturbances in the flow decrease when the available resources for $\mathrm{Z} 4$ decrease. The bold cells of this table show the paths for RO10 in which a flow with a deficit exists. A flow with a deficit exists in 5 pairs RO (bold cells in the first line) as the level of the available resources equals 26.4. The increase in the level to value 27.4 causes a decrease in the number pair RO with a deficit to three (the sec- 


\section{Pawlewski and Fertsch}

ond line in the table). The next decreases of RO number pairs are for the values 31.4 ( 2 pairs) and 32.4 ( 1 pair). The level of the available resources level equal 34.4 liquidates the last RO pair in which the flow with a deficit exists.

\section{FURTHER RESEARCH}

In following paper, the authors present the method to model and simulate production logistics systems and describe its application for the analysis of changing available critical production resource. The next step of the research will regard the examination of the potential of a proposed method for spatial redesign of logistics systems. A common problem that appears in logistics systems is the fact that an initially designed system is not corrected when simultaneously the tasks performed by the system are changing according to variable clients needs. The following situation leads to:

- Limited availability of resources in particular locations

- The limited productivity of the systems which may appear between the nominal (designed) capacity and the real system throughput

- Non-optimal investment decisions regarding increase of capacities in particular location despite the overcapacities available in other locations in the system.

The output of the analyses with use of described method will be used for spatial redesign of resources localizations in a logistics system in order to improve the overall system productivity.

\section{REFERENCES}

Byrne M.D., and M.A. Bakir. 1999. Production planning using a hybrid simulation - analytical approach. International Journal of Production Economics 59:305-311

ELA. 1991. Terminology in Logistics. Brussel. European Logistics Association.

Ingalls, R.G. 2008. Introduction to simulation. In Proceedings of the 2008 Winter Simulation Conference, ed. S. J. Mason, R. R. Hill, L. Monch, O. Rose, T. Jefferson and J. W. Fowler, Institute of Electrical and Electronics Engineers, Inc.

Kosturiak, J., and M. Gregor. 1999. Simulation in production system life cycle. Computers in Industry 38:159-172.

Korzeniowski, A. M., Skrzypek, and G. Szyszka. 1996. Packagings in logistics systems. Poznan, Institute of Logistics and Warehousing

Lee, S., Y. Son, and R. Wysk. 2007. Simulation-based planning and control: From shop floor to top floor. Journal of Manufacturing Systems 26:85-98

Pacholski, L., W. Cempel, and P. Pawlewski. 2009 Reengineering: Reforming business and production processes in company. Poznan, Publishing House of Poznan University of Technology.

\section{AUTHOR BIOGRAPHIES}

PAWEL PAWLEWSKI works as an Assistant Professor at the Department of Computing and Management, Poznan University of Technology. He holds a PhD in Mechanical Engineering, specialization "organization of production systems" from the Poznan University of Technology. His research interests include organization of manufacturing systems, monitoring of operations management, reengineering and IT application for logistics His e-mail address is <pawel.pawlewski@put.poznan.pl>.

MAREK FERTSCH is a Professor at the Department of Computer Science and Management at the Poznan University of Technology. He holds a PhD and DSc in Mechanical Engineering from the Poznan University of Technology. His research interests include manufacturing systems, production planning and logistics. He is a member of ISIR. His e-mail address is marek. fertsch@put. poznan.pl>. 